\title{
Differential serological and neutralizing antibody dynamics after an infection by a single SARS-CoV-2 strain
}

Emmanuelle Billon-Denis

IRBA

Audrey Ferrier-Rembert

IRBA

Annabelle Garnier

IRBA

Laurence Cheutin

IRBA

Clarisse Vigne

IRBA

Emilie Tessier

IRBA

Jessica Denis

IRBA

Cyril Badaut

IRBA

Clémence Rougeaux

IRBA

Anne Depeille

IRBA

Hawa Timera

IRBA

Laetitia Boutin

IRBA

Isabelle Drouet

IRBA

Noémie Verguet

IRBA

Flora Nolent

IRBA

Olivier Gorgé 
IRBA

\section{Olivier Ferraris}

IRBA

Jean-Nicolas Toumier ( $\nabla$ jntournier.irba@gmail.com )

IRBA https://orcid.org/0000-0002-4542-2421

\section{Case Report}

Keywords: SARS-CoV-2, COVID-19, neutralizing antibody, IgG, receptor-binding domain

Posted Date: September 16th, 2020

DOI: https://doi.org/10.21203/rs.3.rs-77625/v1

License: (c) (1) This work is licensed under a Creative Commons Attribution 4.0 International License. Read Full License

Version of Record: A version of this preprint was published at Infection on January 2nd, 2021. See the published version at https://doi.org/10.1007/s15010-020-01556-8. 


\section{Abstract}

\section{Background}

We report here the case of two coworkers infected by the same SARS-CoV-2 strain, presenting two different immunological outcomes.

\section{Case}

One patient presented a strong IgG anti-receptor-binding domain immune response correlated with a low and rapidly decreasing titer of neutralizing antibodies. The other patient had similar strong IgG antireceptor-binding domain immune response but high neutralizing antibody titers.

\section{Discussion and Conclusion}

Thus, host individual factors may be the main drivers of the immune response varying with age and clinical severity.

\section{Introduction}

The emerging severe acute respiratory syndrome coronavirus type 2 (SARS-CoV-2) in China at the end of 2019 has caused the current pandemic of coronavirus infectious disease (COVID)-19, which has infected every continent inhabited by virus specific immunologically-naïve humans [1].

The immune system induction following the SARS-CoV-2 infection is still not well known, although it is established that between 11 to 19 days after onset of symptoms most of patients get a specific and neutralizing antibody $(\mathrm{Ab})$ response [2]. The dynamic of $\mathrm{IgM}$ and $\mathrm{IgG}$ specific immune responses can vary along different factors, leading to various clinical severities of disease [3, 4]. Neutralizing Abs (nAbs) are of paramount importance for virus clearance, but their role in COVID-19 is not clearly established [5]. In most studies however, the specific antibody response is correlated with the emergence of nAbs [6, 7].

We report here the case of two co-workers, infected with the same SARS-CoV-2 strain, presenting two different clinical pictures and immunological outcomes. Interestingly, in one case the IgG response was not correlated with the detection of nAbs in our assay.

\section{Case Report}

Patient 1 was a 26 years old female with no known risk factor. She presented on April 7, 2020 an isolated anosmia-agueusia. Three days later she felt a deep asthenia. She tested positive for SARS-CoV-2 by reverse transcriptase-polymerase chain reaction (RT-PCR) on April 12, 2020. She continued to experience a profound asthenia for 15 days, and completely healed except for the dysnosmia, which was still partially present at day 100 . 
Patient 2 was a male, 51 with no risk factor besides age. He worked with the patient 1 on April 8 . He started to slightly cough on April 11, 2020. The following day, he felt tired, sub-febrile with an increasing cough. He consulted for a suspicion of COVID-19 at a hospital emergency department on April 12, 2020. At the initial examination, patient 2 had a polypnea at 32 respirations/minutes. The blood gas showed a hypoxemia with a PaO2 at $72 \%$, while a lymphopenia at 680 lymphocytes $/ \mathrm{mm} 3$ was noted on the blood cell count. The chest computed-tomography scanner was normal, and the nasopharyngeal RT-PCR was positive for SARS-CoV-2. Patient 2 was discharged from the emergency room with a diagnosis of a mild form of COVID-19. He recovered at home within 15 days without major clinical complication, besides a month-long asthenia.

The SARS-CoV-2 strains from both patients were sequenced from naso-pharyngeal samples by MinION technology, following Artic protocol by PCR tiling [8]. Data were analyzed according to the bio-informatic protocol developed by the Artic consortium. Both patients were infected by the same strain, its sequence harboring 7 SNPs compared to the reference genome Wuhan/Hu-1/2019 (NCBI Nucleotide - NC_045512, GenBank -MN908947) and belonging to the G3b phylum [9], thus carrying the recently identified D614G mutation [10]. On August 1st and 2nd, 2020, the two sequences were deposited on the GISAID platform with accession ID EPI_ISL_505003 and EPI_ISL_506041 for patient 1 and 2 respectively.

The humoral immune response of both patients was followed serially for up to 100 days. An in-house enzyme-linked immuno-sorbent assay (ELISA) was developed for detecting IgG against SARS-CoV-2 adapted from a work made by Florian Krammer [11]. The ELISA detection was based on the receptorbinding domain (RBD) recognition of the SARS-CoV-2 spike (S)-glycoprotein. ELISA results are presented as optical density (OD) ratio obtained by dividing the average OD of duplicate wells from that of the corresponding blank non-coated wells.

For each time point, the presence of nAbs was also sought by a seroneutralisation assay performed on Vero cells using the Institut Pasteur SARS-CoV-2 reference strain in a BSL3 facility.

Both patients rapidly developed an IgG immune response against RBD as they were positive within 12 days, then marked a steep increase followed by a plateau and a slow decrease (Figure 1). Patient 1 had a stronger IgG anti-RBD response while presenting a pauci-symptomatic infection. Patient 2 had also a robust anti-RBD response, while presenting mild clinical symptoms, that included blood desaturation as measured initially. Strikingly, patient 1 did only develop a very moderate neutralizing immune response with low nAb titers that turned negative by day 100 , suggesting that virus clearance and the clinical recovery occurred independently of the nAb response.

\section{Discussion}

The case presented underscores the role of unknown individual host factors or the potential other human coronavirus past infection in the serological response against SARS-CoV-2. As both patients were infected in a close time-line by the same virus, we can rule out the role of any virus effect on the immune response. 
The protective role of antibodies and cellular immune response against SARS-CoV-2 is unknown, but antibodies are usually a reasonable correlate of immunity [2]. As RBD is the site of interaction of the Sglycoprotein with the angiotensin-converting enzyme (ACE)-2, which plays the role of virus receptor, a large number of neutralizing epitopes are located on $\operatorname{RBD}[12,13]$. In the vast majority of studies, the anti-RBD antibody levels correlate to serum viral neutralizing activity $[6,7]$.

\section{Conclusion}

Here, we demonstrate that RBD antibody levels and nAbs might not be correlated. The age, the clinical severity of the case [14], the sex [15], and several individual unknown host factors may influence the strength of the immune responses independently of the virus genotype.

Some other questions are still to be answered such as the long-term duration of the Ab response, and the correlate of protection. These data are crucial for evaluating the variability of the immunity in future vaccine studies.

\section{Declarations}

\section{Funding}

This work was supported by the Délégation générale pour l'armement [Biomedef COVID5]

\section{Compliance with ethical standards}

Conflicts of interest None of the authors has any conflict of interest relevant to the content of this work. There are no competing interests.

\section{Consent for publication Obtained}

\section{References}

1. Morens DM, Daszak P, Markel H, Taubenberger JK. Pandemic COVID-19 Joins History's Pandemic Legion. mBio 2020; 11(3).

2. Vabret N, Britton GJ, Gruber C, et al. Immunology of COVID-19: Current State of the Science. Immunity 2020; 52(6): 910-41.

3. Long QX, Liu BZ, Deng HJ, et al. Antibody responses to SARS-CoV-2 in patients with COVID-19. Nat Med 2020; 26(6): 845-8.

4. To KKW, Tsang OTY, Leung WS, et al. Temporal profiles of viral load in posterior oropharyngeal saliva samples and serum antibody responses during infection by SARS-CoV-2: an observational cohort study. Lancet Infectious Diseases 2020; 20(5): 565-74.

5. Jiang S, Hillyer C, Du L. Neutralizing Antibodies against SARS-CoV-2 and Other Human Coronaviruses. Trends Immunol 2020; 41(5): 355-9. 
6. Okba NMA, Muller MA, Li W, et al. Severe Acute Respiratory Syndrome Coronavirus 2-Specific Antibody Responses in Coronavirus Disease Patients. Emerg Infect Dis 2020; 26(7): 1478-88.

7. Wolfel R, Corman VM, Guggemos W, et al. Virological assessment of hospitalized patients with COVID-2019. Nature 2020; 581(7809): 465-9.

8. Quick J, Grubaugh ND, Pullan ST, et al. Multiplex PCR method for MinION and Illumina sequencing of Zika and other virus genomes directly from clinical samples. Nat Protoc 2017; 12(6): 1261-76.

9. Gambaro F, Behillil S, Baidaliuk A, et al. Introductions and early spread of SARS-CoV-2 in France, 24 January to 23 March 2020. Euro Surveill 2020; 25(26).

10. Korber B, Fischer WM, Gnanakaran S, et al. Tracking Changes in SARS-CoV-2 Spike: Evidence that D614G Increases Infectivity of the COVID-19 Virus. Cell 2020.

11. Amanat F, Stadlbauer D, Strohmeier S, et al. A serological assay to detect SARS-CoV-2 seroconversion in humans. Nat Med 2020; 26(7): 1033-6.

12. Yuan $M$, Wu NC, Zhu $X$, et al. A highly conserved cryptic epitope in the receptor binding domains of SARS-CoV-2 and SARS-CoV. Science 2020; 368(6491): 630-3.

13. Ju B, Zhang Q, Ge J, et al. Human neutralizing antibodies elicited by SARS-CoV-2 infection. Nature 2020.

14. Wang X, Guo X, Xin Q, et al. Neutralizing Antibody Responses to Severe Acute Respiratory Syndrome Coronavirus 2 in Coronavirus Disease 2019 Inpatients and Convalescent Patients. Clin Infect Dis 2020.

15. Park MD. Sex differences in immune responses in COVID-19. Nature Reviews Immunology 2020.

\section{Figures}




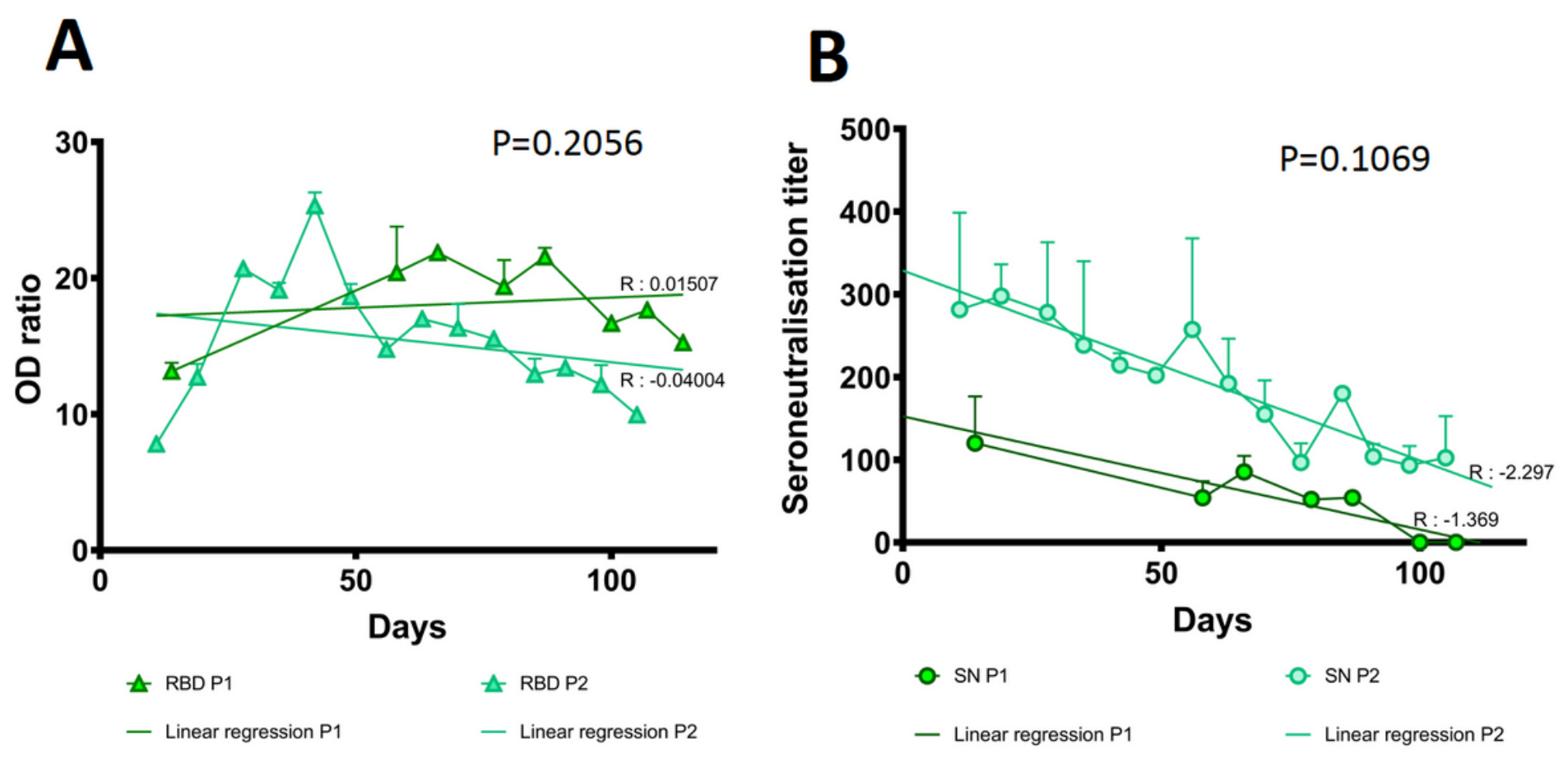

Figure 1

Patients 1 and 2 IgG ELISA OD ratio against SARS-CoV-2 and seroneutralizing titers (A) Green triangle, OD ratio RBD signal patient 1 (RBD P1); Blue triangle, OD ratio RBD signal patient 2 (RBD P2). (B) Green sphere, seroneutralizing titers patient 1 (SN P1); Blue sphere, seroneutralizing titers patient 2 (SN P2). 